\title{
A Comparative Analysis of Human Trafficking: The United States of America (USA) and the Republic of South Africa (RSA)
}

\author{
Mark M. Lanier ${ }^{1}$, C. Thomas Farrell ${ }^{2, *}$ and Christiaan Bezuidenhout ${ }^{3}$ \\ ${ }^{1}$ Cyber Institute, University of Alabama, Tuscaloosa, AL, USA \\ ${ }^{2}$ Department of Public Health, Western Kentucky University, Bowling Green, KY 42101, USA \\ ${ }^{3}$ Department of Social Work \& Criminology, University of Pretoria, Pretoria 0002, Gauteng, South Africa
}

\begin{abstract}
Human trafficking is a serious global problem that transcends international borders and disciplinary boundaries. It presents a conglomeration of problems generally dealt with by public health, criminal justice, social service and immigration agencies. Victim advocates state that millions are victimized each year. The data suggest that law enforcement agencies perceive human trafficking to be of greater, or equal, concern for the myriad of social institutions and participants affected by human trafficking than for law enforcement, itself. Policy recommendations are to refocus the law enforcement response - which may include various approaches that can simultaneously benefit public health - by incorporating an Epidemiological Criminology framework to help to guide the development of more systematic and integrative insight into the world of human trafficking.
\end{abstract}

Keywords: Human trafficking, public health, epidemiological criminology.

\section{INTRODUCTION}

In the United States (USA), Florida has one of the highest concentrations of human trafficking victims. Law Enforcement officers are often the government entity most likely to contact victims first. However law enforcement officers may not know the cues needed to properly identify a human trafficking situation or encounter. Quite often, the initial contact is related to "illegal" activity on the part of the victims (e.g. illicit migrant labor, prostitution, illegal immigration, drug use, etc.). Following law enforcement policy and law, the actual trafficking victim may be detained, arrested and/or deported. This policy strengthens the traffickers' hold and power over the victims since captives are routinely told by their abductors to shun the police, and not to seek help, as law enforcement officials will arrest them. This control strategy must be negated. It is imperative for victims to seek help and for law enforcement officers to be trained, equipped and legally mandated to render aid. Law enforcement must be an ally to victims and a solution to the problem, rather than a threat utilized by the traffickers to help maintain control. However, a quandary exists. If victims are engaged in illegal activity, how can law enforcement ignore their legal mandate to enforce the law?

There are also similar problems in South Africa as in Florida. In the past, RSA used existing laws like the

*Address correspondence to this author at the Department of Public Health, Western Kentucky University, Bowling Green, KY 42101, USA; Tel: (270)7454797; Fax: (270) 745-4437; E-mail: Colin.farrell@wku.edu

E-ISSN: $1929-4409 / 14$ legislation on sexual offences and the Children's Act to prosecute perpetrators. However, there were gaps in measures to prevent and combat trafficking, and to provide protection and assistance to trafficking victims. To address these gaps in the RSA The Prevention and Combating of Human Trafficking Act, Act no. 7 was promulgated which provides a legal framework that contains measures that prevent trafficking, prosecute traffickers, and protect trafficking victims (Government Gazette 2013). The new legislation makes trafficking in persons a criminal offence. In addition, it also addresses offences such as debt bondage; the possession, destruction, concealment of and tampering with travel documents; and using the services of victims of trafficking, among others. Offenders found guilty of this modern day slavery will be fined up to R100 million (US\$ 10 million) or risk life imprisonment or both, if convicted. Perpetrators may also be required to pay their victims compensation. The current challenges and problems include the implementation of the legislation and to inform police officials about the scope of the legislation. Although the necessary tools have been developed to police human trafficking and traffickers many police officers still prefer to put pressure on the detained victim and follow very similar tactics as Florida law enforcement officers: detain, arrest and/or deport the victim without investigating the trafficker or source of trafficking.

Human trafficking has garnered a greater focus as our society has continued to become increasingly more globalized (United States Department of State 2013; Futter 2008). Globalization has increased the incidence of human trafficking, largely, by increasing international 
trade (Nazemi 2012) and growing demand. Not only does increased international trade open the borders, but it also results in increased migration. The movement of people tends to follow the spread of trade in an attempt to improve their economic situations, which may leave individuals vulnerable to exploitation (Chuang 2006; Nazemi 2012).

Though accurate numbers are impossible to identify, an estimated 20.9 million people exist in forced labor circumstances at any given moment, with the highest rates seen in central and southeastern European (non-EU) countries and the Commonwealth of Independent States (4.2 per 1000) and the lowest rates being found in Developed Economies and the European Union (1.5 per 1000) (ILO, 2012). Recent estimates indicate that between 14,500 and 17,500 trafficking victims are brought into the United States, annually, with approximately $20 \%$ of those cases coming through Florida (FL) (Simon 2008). With regard to RSA, the IOM estimates that about 1000 young women are trafficked from Mozambique to South Africa and between 850 and 1100 women from Thailand each year (IOM 2003). Women from other destinations such as European countries are also transported into RSA to work in strip clubs and the sex industry but scant scientific knowledge on the modus operandi of the criminal underground successfully keeps this trade in check. RSA is also a common destination for trafficked or smuggled individuals from other neighbouring countries that are in dire economic straits, such as Zimbabwe, Lesotho and Swaziland, with children and women accounting for the majority of all victims detected in Africa (Swart 2012).

Most laws focus on prosecuting traffickers/ trafficking organizations and protecting/ reintegrating victims into society (Chuang 2006); however, current laws and programs tend to overlook the base causes of trafficking. Socioeconomic conditions have an important role in human trafficking. Chuang argues the problem needs to be addressed at its base; however, "oft-repeated pledges to prevent trafficking by addressing its root causes seldom evolve from rhetoric into reality" (2006: 138). Though there have been hundreds of millions invested in the criminal justice response, research has yet to show an appreciable reduction in the total numbers of individuals trafficked worldwide (Chuang 2006; Todres 2011). Furthermore, despite all the resources committed to human trafficking, and estimates of $20+$ million victims annually, in 2009 there were only 4,166 successful trafficking convictions worldwide (United States
Department of State 2010) and prior studies indicate that fewer than $10 \%$ of law enforcement agencies have investigated cases of human trafficking (Farrell et al. 2010). Considering this, it becomes clear current actions towards stemming the tide of human trafficking are ineffective and a new perspective is needed (Chuang 2006; Todres 2011).

Supported by our subsequent analysis, we propose a solution with global relevance by striking a balance between both the law enforcement arm (the iron fist) and the need for intervening from a public health perspective (the velvet glove) in both the USA and RSA.

\section{RATIONALE FOR EPIDEMIOLOGICAL CRIMINO- LOGY}

Akers and Lanier (2009) first presented an argument for criminal justice and criminology having roots in public health and epidemiology. Epidemiological Criminology, or "EpiCrim", was presented as a means of "coming full circle" and reuniting these disciplines and provides the theoretical basis for this study. The following section gives a synopsis of their argument. There is an increasing overlap and blurring of distinctions between public health and criminology (Lanier, Lucken and Akers 2009). Both criminal justice and public health academics and professionals work with marginalized populations; people at high risk to multiple dangers including drug use, health problems, exploitation, and incarceration. AIDS/HIV, for example, provides the first illustration of the interconnection between the two fields since AIDS/HIV was the health threat which first dramatically confronted criminal justice agencies (Lanier 2006), especially within prisons and jails (Braithwaite, Hammett, and Mayberry 1996). Victims of human trafficking, likewise, fit well under each category and so thus comprise a population of special interest to a public health and criminological analytical framework.

Although numerous illustrations can be used to convey this merging, there is a scarcity of explicit theoretical and methodological linkage. To address this deficiency, we suggest the development of a new framework which links methods, and statistical models of public health, which are complemented by their criminal justice counterpart (Akers and Lanier 2009). In this study, we outline the commonalties and distinctions, followed by an example dealing with human trafficking that integrate the disciplinary similarities. We propose Epidemiological Criminology 
as a bridging framework and a useful conceptual model for addressing problems emanating from human trafficking.

\section{METHODS}

In 2009, the Florida Department of Law Enforcement (FDLE) expressed an interest and need to scientifically ascertain the nature and extent of human trafficking within the state of Florida. A comprehensive survey was conducted of all Florida Sheriff Departments having countywide jurisdiction, and all the units responsible for the policing of human trafficking. Due to policy related, programmatic, and legal interest in "import" and "export" locales, the study was replicated in the RSA using similar methodological and analytical procedures.

\section{Instrument Development and Administration}

All existing survey instruments that could be located dealing with human trafficking and law enforcement were examined. None were found to be specific enough, not methodologically very elaborate, so a new instrument was developed. After a preliminary instrument was created, FDLE and several senior law enforcement officials reviewed it for content validity and a few changes were made. Next, the survey instrument was pretested with several law enforcement officers to help assess readability and to further assess content validity. After this pretest some answer formats were revised to make the instrument easier to complete. Finally, the completed instrument was sent to a researcher in South Africa and after his review the survey instrument was adapted accordingly to also make it applicable to South African conditions. This final step resulted in a few additional questions being added.

The first section of the questionnaire contained thirteen (13) items measuring the type of department (size, locale, etc.) and county level characteristics (urban, border, etc.). Section 1 also asked if a special unit for dealing with "undocumented citizens" existed and the percentage of the employees who are bilingual. Finally section 1 also requested demographic information about the person actually completing the form (Sheriff, staff or sworn police officer, years of experience, gender, etc.). The second section of the instrument contains 38 items, two of which are open ended. The third open ended section (six items) asks about special problems created by human trafficking, specific case examples, means of victims transport, how undocumented immigrants are screened to determine whether they are or not, how the case came to the attention of law enforcement and where the victim's country of origin was. In the conclusion of the questionnaire the fourth section simply asked respondents to include anything else important that the questionnaire omitted (it was also open ended).

Ultimately, sixty-seven (67) surveys were administered to the Florida Sheriff Departments, and fifty-four (54) were returned, for a response rate of $80.6 \%$. In RSA, two hundred (200) surveys were distributed amongst Provincial Commissioners, senior officers, and senior law enforcement management. Of the two hundred surveys, eighty-four (84) were completed and returned for a response rate of $42 \%$. A representative from the National Head Office at the South African Police Services assisted the researcher from South Africa to contact the relevant units/ departments in each of the 9 Provinces that specifically police human trafficking. A number of questionnaires were submitted via the internal SAPS postage system for completion to all the relevant (selected units) police stations in the 9 provinces. All the provinces of South Africa were included to ensure a representative response rate and generalizable findings. South Africa consists of 9 provinces which excludes two countries within the boundaries of South Africa, namely Lesotho and Swaziland. There are 1152 police stations in the 9 provinces which covers a land surface of 1219090 square kilometers. There are about 157,500 sworn police officers and about 41800 civilians in the police service who must serve a population of 51.19 million people.

The responding agencies, within Florida, reflected the entire state with regards to urban/rural, coastline/inland, large/small, and on every other measured departmental and county characteristics. The data was cleaned and entered 3 times, by 3 separate individuals, (a version of the standard double data entry process) to assure a clean data set. In South Africathe data set was cleaned and statistically dissected. The process was repeated by a colleague from another university to ensure accurate data entry.

\section{Analysis}

Multiple quantitative steps were undertaken to evaluate the difference, and similarities, between the perception of HT in RSA and FL. Initially, the reported mean values of HT concern, for each variable, were compared across RSA and FL to determine whether 
there is a difference in said values. Additionally, in the interest of determining whether the arguments put forth by the theoretical approach of EpiCrim are valid - in short, that the criminal justice system and the public health system would benefit from collaborative efforts in addressing $\mathrm{HT}$, thus benefiting the public and the political facets of society - ANOVA was utilized to determine whether there is a difference in reported levels of concern for each EpiCrim relevant concept.

\section{FINDINGS}

The vast majority of Florida Sheriff Department staff who completed the questionnaire were male (92.6\%) and had over 13 years law enforcement experience (94.4\%), as shown in Table 1. Most of the responding agencies serviced urban (over 50,000 citizens) areas. Fewer than ten percent $(9.6 \%)$ were located in rural areas and a combined $25 \%$ policed both small towns and medium cities. Nearly half the responding agencies had between 101 and 500 officers (47.2\%) and twelve agencies $(22.6 \%)$ were large (over 500 sworn officers). Nearly all $(81.5 \%)$ of the responding departments had less than $10 \%$ of the department who spoke more than one language. In RSA, the questionnaire respondents were predominately male $(79.8 \%)$ and, similar to Florida, most had more than 13 years of law enforcement experience (61.9\%). A gross majority of the agencies served medium cities or urban areas $(98.7 \%)$. Unlike Florida, the plurality of the responding agencies was staffed by $20-100$ sworn officers, with a relatively equal distribution across all other size

Table 1: Descriptive Statistics

\begin{tabular}{|c|c|c|c|c|}
\hline \multirow[b]{2}{*}{ Variables } & \multicolumn{2}{|c|}{ FL } & \multicolumn{2}{|c|}{ RSA } \\
\hline & $n$ & Group \% & $n$ & Group \% \\
\hline \multicolumn{5}{|l|}{ Gender } \\
\hline Male & 50 & 92.6 & 67 & 79.8 \\
\hline Female & 4 & 7.4 & 17 & 20.2 \\
\hline Total & 54 & 100 & 84 & 100 \\
\hline \multicolumn{5}{|l|}{ Years of Experience } \\
\hline $0-3$ & - & - & 1 & 1.2 \\
\hline $4-7$ & - & - & 11 & 13.1 \\
\hline $8-12$ & 3 & 5.6 & 19 & 22.6 \\
\hline $13-18$ & 10 & 18.5 & 8 & 9.5 \\
\hline$>18$ & 41 & 75.9 & 44 & 52.4 \\
\hline Total & 54 & 100 & 83 & 100 \\
\hline \multicolumn{5}{|l|}{ Geographic Area } \\
\hline Rural & 5 & 9.6 & - & - \\
\hline Small City/Twp & 7 & 13.5 & 1 & 1.2 \\
\hline Medium City/Twp & 6 & 11.5 & 18 & 22.2 \\
\hline Urban & 34 & 65.4 & 62 & 76.5 \\
\hline Total & 52 & 100 & 81 & 100 \\
\hline \multicolumn{5}{|l|}{ \# Sworn Officers } \\
\hline$<20$ & 6 & 11.3 & 13 & 16.5 \\
\hline $21-100$ & 10 & 18.9 & 35 & 44.3 \\
\hline $101-500$ & 25 & 47.2 & 15 & 19.0 \\
\hline$>500$ & 12 & 22.6 & 16 & 20.3 \\
\hline Total & 53 & 100 & 79 & 100 \\
\hline \multicolumn{5}{|l|}{ Bi/Multilingual (\%) } \\
\hline$<10$ & 44 & 81.5 & 6 & 7.5 \\
\hline $11-25$ & 4 & 7.4 & 9 & 11.3 \\
\hline $26-50$ & 5 & 9.3 & 11 & 13.8 \\
\hline $51-75$ & - & - & 20 & 25.0 \\
\hline$>75$ & - & - & 34 & 42.5 \\
\hline Total & 53 & 100 & 80 & 100 \\
\hline
\end{tabular}


classifications. Lastly, in contrast to the near absence of bi- or multilingual officers in Florida, $42.5 \%$ of all responding agencies reported more than $75 \%$ of the department speaking more than one language, with $77.5 \%$ of departments reporting more than $50 \%$.

Tables 2 and 3 reflect the perceived level of concern, regarding $\mathrm{HT}$, as it pertains to the respondent's agency, the citizens, politicians, public health facilities, and media outlets, with responses distributed across department size and geographical location of the department in Florida and South Africa, respectively. Upon initial comparison, it is clear that the South African respondents were far more likely to report that HT is of high concern, for all arenas of evaluation, than the respondents in Florida. Conversely, more than $50 \%$ of all Florida agencies considered HT to be of low concern for all EpiCrim variables, with a staggering $77 \%$ stating that, from the perspective of the Sheriff Department, HT is of low concern. The above impressions are reflected in Table 4, which conveys that the mean reported level of concern is higher in all categories within RSA. It is worth mentioning that in both samples (RSA and FL) the mean reported value for law enforcement concern is, numerically, the lowest amongst all reported means. Supporting the apparent differences in Table 4, there is a difference between RSA and FL in the reported levels of concern regarding HT as it pertains to all categories - law enforcement concern, public concern, political concern, public health concern, and media concern with RSA reporting higher values than FL in all cases (Table 5).

Table 6 communicates the results of the ANOVA analyses. In the responses from Florida, there is a significant difference in the reported levels of concern amongst the various EpiCrim variables and the level of concern amongst the law enforcement agents. It is important to emphasize that, while all categories had higher average levels of perceived concern, in comparison to the sheriff's level of concern, the public health system and political arena were found to be significantly greater. In RSA, there is no significant difference between the reported level of concern, as perceived by the law enforcement agents, and the

Table 2: Human Trafficking Concern - FL Sheriff Departments

\begin{tabular}{|c|c|c|c|c|c|c|c|c|}
\hline & \multicolumn{4}{|c|}{ DEPARTMENT SIZE } & \multicolumn{4}{|c|}{ GEOGRAPHIC AREA } \\
\hline & $<20$ & $21-100$ & $101-500$ & $>500$ & $\mathbf{R}$ & $\mathbf{s}$ & M & u \\
\hline \multicolumn{9}{|c|}{ Sheriff perception of HT problem } \\
\hline Low & .12 & .20 & .33 & .12 & .08 & .14 & .10 & .44 \\
\hline Medium & 0 & 0 & .16 & .08 & .02 & 0 & .02 & .20 \\
\hline High & 0 & 0 & 0 & 0 & 0 & 0 & 0 & 0 \\
\hline \multicolumn{9}{|c|}{ Level of community concern } \\
\hline Low & .08 & .16 & .33 & .08 & .02 & .10 & .12 & .40 \\
\hline Medium & .02 & .02 & .16 & .12 & .04 & .04 & 0 & .24 \\
\hline High & .02 & .02 & 0 & 0 & .04 & 0 & 0 & 0 \\
\hline \multicolumn{9}{|l|}{ Level of political concern } \\
\hline Low & .08 & .13 & .29 & .04 & .04 & .09 & .09 & .32 \\
\hline Medium & .02 & .04 & .13 & .13 & .04 & .04 & .02 & .21 \\
\hline High & 0 & .04 & .08 & .02 & .02 & 0 & .02 & .11 \\
\hline \multicolumn{9}{|c|}{ Level of public health concern } \\
\hline Low & .06 & .15 & .33 & .06 & .02 & .09 & .11 & .38 \\
\hline Medium & .06 & .04 & .10 & .10 & .06 & .06 & .02 & .17 \\
\hline High & 0 & .02 & .06 & 0 & .02 & 0 & 0 & .06 \\
\hline \multicolumn{9}{|l|}{ Level of media concern } \\
\hline Low & .06 & .16 & .34 & .06 & .02 & .06 & .12 & .41 \\
\hline Medium & .04 & .02 & .10 & .12 & .04 & .08 & 0 & .16 \\
\hline High & .02 & .02 & .04 & .02 & .04 & 0 & 0 & .06 \\
\hline
\end{tabular}


Table 3: Human Trafficking Concern - RSA Law Enforcement

\begin{tabular}{|c|c|c|c|c|c|c|c|c|}
\hline & \multicolumn{4}{|c|}{ DEPARTMENT SIZE } & \multicolumn{4}{|c|}{ GEOGRAPHIC AREA } \\
\hline & $<20$ & 21-100 & $101-500$ & $>500$ & $\mathbf{R}$ & $\mathbf{S}$ & $\mathbf{M}$ & $\mathbf{U}$ \\
\hline \multicolumn{9}{|c|}{ Sheriff perception of HT problem } \\
\hline Medium & .05 & .15 & .10 & .04 & 0 & 0 & .10 & .25 \\
\hline High & .5 & .14 & .04 & .04 & 0 & 0 & .03 & .25 \\
\hline Medium & .5 & .17 & .12 & .03 & 0 & 0 & .10 & .28 \\
\hline High & .08 & .18 & .04 & .08 & 0 & 0 & .06 & .30 \\
\hline \multicolumn{9}{|c|}{ Level of political concern } \\
\hline Low & .05 & .09 & .05 & .09 & 0 & .01 & .06 & .20 \\
\hline Low & .07 & .08 & .05 & .08 & 0 & .01 & .1 & .15 \\
\hline Medium & .04 & .25 & .10 & .08 & 0 & 0 & .06 & .43 \\
\hline High & .07 & .13 & .04 & .03 & 0 & 0 & .06 & .18 \\
\hline \multicolumn{9}{|c|}{ Level of media concern } \\
\hline Low & .09 & .06 & .04 & .04 & 0 & 0 & .08 & .15 \\
\hline Medium & .01 & .21 & .1 & .05 & 0 & .01 & .08 & .30 \\
\hline High & .06 & .18 & .05 & .10 & 0 & 0 & .08 & .31 \\
\hline
\end{tabular}

Table 4: Mean Scores for EpiCrim Relevant Variables

\begin{tabular}{|c|c|c|c|c|}
\hline \multirow{2}{*}{} & \multicolumn{2}{|c|}{ RSA } & \multicolumn{2}{|c|}{ FL } \\
\cline { 2 - 5 } & Mean & Std. Deviation & Mean & Std. Deviation \\
\hline \hline Law Enforcement Concern with HT & 5.04 & 3.225 & 2.17 & 1.757 \\
\hline Citizen's concern with HT? & 5.81 & 3.168 & 3.06 & 2.118 \\
\hline Political concern with HT? & 5.58 & 3.041 & 4.00 & 2.850 \\
\hline Public Health concern with HT? & 5.45 & 2.920 & 3.63 & 2.729 \\
\hline Media concern with HT? & 6.17 & 3.011 & 3.31 & 2.557 \\
\hline
\end{tabular}

Table 5: Independent Samples Test of Difference (RSAFL)

\begin{tabular}{|c|c|c|}
\hline & $\begin{array}{c}\text { Mean } \\
\text { Difference } \\
(95 \% \mathrm{Cl})\end{array}$ & $\begin{array}{c}\text { Std. Error } \\
\text { Difference }\end{array}$ \\
\hline \hline Law Enforcement Concern & $\begin{array}{c}2.80^{* * *} \\
(1.94,3.65)\end{array}$ & .432 \\
\hline Citizen's Concern with HT & $\begin{array}{c}2.67^{* * *} \\
(1.76,3.58)\end{array}$ & .459 \\
\hline Political Concern with HT & $\begin{array}{c}1.66^{* * *} \\
(.59,2.73)\end{array}$ & .540 \\
\hline Public Health Concern with HT & $\begin{array}{c}1.94^{* * *} \\
(.91,2.96)\end{array}$ & .517 \\
\hline Media Concern with HT & $\begin{array}{c}3.00^{* * *} \\
(2.06,3.95)\end{array}$ & .478 \\
\hline
\end{tabular}

Sig. ${ }^{*} .05 ;{ }^{* *} .01 ;{ }^{* * \star} .001$. reported perceived level of concern for the EpiCrim relevant variables.

\section{DISCUSSION AND RECOMMENDATIONS}

The findings of the means analyses support two separate conclusions. First, there appears to be a significant difference in the perceived threat of human trafficking between RSA and FL (Table 5). With average scores in RSA falling in the range of 'medium concern,' while the mean scores in FL tended to concentrate within the proximity of 'low concern,' such findings clearly indicate that, within the context of law enforcement, the perceived threat of HT is much greater within RSA. This is likely to reflect multiple 
Table 6: ANOVA and Tukey's HSD

\begin{tabular}{|c|c|c|c|c|c|c|}
\hline \multirow{2}{*}{} & HSD Mean Difference & \multicolumn{2}{|c|}{ Std. Error } & \multicolumn{2}{c|}{ 95\% CI } \\
\cline { 2 - 7 } & $\boldsymbol{F L}$ & $\boldsymbol{R S A}$ & $\boldsymbol{F L}$ & $\boldsymbol{R S A}$ & $\boldsymbol{F L}$ & $-.54,2.08$ \\
\hline \hline Citizen's concern with HT? & 0.885 & .771 & .476 & .477 & $-0.42,2.19$, & $-.77,1.85$ \\
\hline Political concern with HT? & $1.827^{* *}$ & .542 & .483 & .477 & $0.50,3.15$ & $-.86,1.77$ \\
\hline Public Health concern with HT? & $1.460^{*}$ & .452 & .483 & .479 & $0.13,2.79$ & $-.18,2.44$ \\
\hline Media concern with HT? & 1.141 & 1.133 & .478 & .477 & & \\
\hline
\end{tabular}

Sig. ${ }^{*} .05 ;{ }^{* *} .01$.

aspects previously discussed. The Republic of South Africa has a much more publicized history with human trafficking, thus bringing the issue to the forefront of political agendas and, subsequently, law enforcement focus. The new widely publicized specific Prevention and Combating of Trafficking in Persons Act that was promulgated in 2013 has been before Parliament for six years, and has been the focus of advocacy campaigns around issues of human trafficking for more than a decade. The legislation is largely the result of work done by the South African Law Reform Commission, together with numerous civil society roleplayers. We deduce that the constant debate about the Trafficking Bill before it became an Act probably made the law enforcement role-players more aware of the phenomenon. Furthermore, the turmoil and instability within the immediate proximity of RSA (e.g. the economic chaos and social disorder in Zimbabwe and Mozambique) is likely to have resulted in a greater prevalence of HT in RSA compared to the USA; thus, creating a greater need for concern among the various departments and institutions within RSA. Also, after democratization South African borders have become porous and easy to access.

Despite the difference in levels of concern between the two countries, there is a shared reality that exists within both settings. In RSA and FL, there is an apparent acknowledgment of the importance of additional social institutions, beyond the criminal justice system, in addressing the contextual issue of $\mathrm{HT}$. In RSA and FL, the reported concern, as it pertains to the law enforcement agencies, is no greater, and in some cases is less than, the perceived level of concern for the additional EpiCrim relevant factors. That is, despite the fact that there is a clear difference in the level of concern regarding $\mathrm{HT}$, the criminal justice institutions within the respective countries reported that such levels of concern are equivalent, if not greater, for the general public, the political arena, the public health establishment, and the media. Such findings support the argument put forth by EpiCrim, which is that HT (and the subsequent identification of victims), which is often conceptualized as a 'legal' issue, would benefit from reshaping the discussion into an issue that spans the criminal justice and public health arenas.

\section{EPIDEMIOLOGICAL CRIMINOLOGY-BASED RES- PONSE}

Emile Durkheim (1864) defined crime as a primary indicator of public health. Epidemiological Criminology was developed with this as one of the foundational premises. With that in mind, prior studies have applied EpiCrim to explain the manner in which HIVIAIDS is used as a weapon in civil uprisings (Chowdhury and Lanier 2013); as well as, explaining the prevalence of drug use among social delinquents (Lanier, Pack, and Akers 2010). In both instances, the concept of exploration can easily fall within the realm of criminal justice or public health. Through the application of EpiCrim, one is able to explain these issues within the framework of both institutions. The same applies to human trafficking.

Human trafficking is an act that is in direct violation of national and international law. Consequently, the connection with criminal justice is apparent - it is, by definition, a legal issue. However, when one considers the consequences of $\mathrm{HT}$, the role and impact of public health comes into greater focus. Considering that an estimated $87 \%$ of all HT victims are trafficked for the purpose of sex trade (Rittossa 2009), and acknowledging the clandestine nature of $\mathrm{HT}$, there is a real risk of contraction, and subsequent transmission, of HIV and other STIs. Additionally, victims of HT have been found to suffer from emotional and psychological disorders, such as depression, anxiety, and PTSD; sense of vulnerability and helplessness; hypervigilance; heightened anxiety and physical abuse. While physical injuries are evident, psychological ones 
are less obvious and often ignored (Mehta 2013; Rittossa 2009). Furthermore, given the lack of health care access, and the conditions of existence experienced by HT victims (Lanier and Farrell, 2014), there is also reason to suspect high rates of communicable diseases, such as tuberculosis and influenza. Since many victims are still young and busy with critical development tasks persistent PTSD from the traumatic trafficking ordeal often leads to an irreversible decrease of hippocampal volume (the frontal part of the brain) and to memory impairment, especially short term memory. This is especially relevant where children have been trafficked and sexually exploited in the ever growing child sex industry. Prostitution of children usually manifests in the form of sex trafficking. Many children from poor countries are kidnapped or deceived into becoming involved in the flourishing child sex trade. In countries like South Africa many children also get involved in "survival sex", in which the child engages in sexual activities to procure basic essentials such as food and shelter because of the significant number of single parent families or child headed households. They become easy targets for ruthless trafficking gangs. Some individuals travel to foreign countries (e.g. from Europe to South Africa) to go on a child sex holiday excursion. Although this industry is huge in South Africa, South America and Asia similar problems exist globally in undeveloped as well as developed countries. The stress among these exploited children also leads to hyperactivity and learning difficulties. Lack of cooperation, overt hostility, an impaired ability to recall events in detail, errors in accounts or fabrications concerning specific events are all likely to occur as a consequence of the trafficking trauma (Mehta 2013).These issues are less likely to exist within the individual if they had not been a victim of HT. In this way, the concerns of the criminal justice system and the concerns of the public health arena are intricately linked.

Beyond recognizing the direct health effects of human trafficking, EpiCrim also provides a framework within which to shape policy recommendations. Like all diseases, criminal acts are not isolated experiences. The existence of such acts occurs within a context, and it is that context that enables the act. This understanding is integral to epidemiological research. By applying epidemiological theory to the concept of human trafficking, we are able to explore the enabling and predisposing factors that lead to not only the act of human trafficking, but being a victim of human trafficking, as well. Through such understanding, it is possible to develop and shape policy to address, specifically, those factors identified as important to the 'development' of HT.

Related to this is the political reality that county level Sheriffs, especially in the United States, may determine which laws to focus on, and which to ignore, based on political persuasions. In the United States any law enforcement agency, not just Federal, are expected to enforce human trafficking laws. The extent to which this enforcement occurs was one purpose of this paper.

The findings of the present research provide strong evidence that public health and policy development are important aspects of tackling HT. Furthermore, it is apparent that the criminal justice system would welcome the incorporation of these institutions and concerned role-players, with the goal of identifying HT victims, dealing with $\mathrm{HT}$ victims, treatment of these victims and combatting the practice. The end result will be better and more effective policing of this secretive crime; the apprehension of the trafficker and appropriate assistance to the victims of trafficking.

\section{Recognition}

Prof Nuran Bayram, Uludag University, Faculty of Economics and Administrative Sciences, Department of Econometrics, Bursa, Turkey (assisted in the scrutiny of the RSA data set).

\section{REFERENCES}

Akers, Timothy A. and Mark M. Lanier. 2009."Epidemiological Criminology: Coming Full Circle." American Journal of Public Health 99(3):397-402. http://dx.doi.org/10.2105/AJPH.2008.139808

Braithwaite Ronald L., Theodore M. Hammett, and Robert M. Mayberry. 1996. Prisons and AIDS: A Public Health Challenge. San Francisco: Jossey-Bass.

Chowdhury, Ishita and Mark M. Lanier. 2012."Rape and HIV as Methods of Waging War: Epidemiological Criminology's Response." Advances in Applied Sociology 2(1):47-52. http://dx.doi.org/10.4236/aasoci.2012.21006

Chuang, Janie. 2006. "Beyond a snapshot: Preventing Human Trafficking in the Global Economy." Indiana Journal of Global Legal Studies 13(1):137-163. http://dx.doi.org/10.2979/GLS.2006.13.1.137

Durkheim, Emile. 1864/1951.Suicide. New York City: The Free Press.

Farrell, Amy, Jack McDevitt, and Stephanie Fahy. 2010."Where are all the victims? Understanding the Determinants of Official Identification of Human Trafficking Incidents." Criminology \& Public Policy 9(2):201-233. http://dx.doi.org/10.1111/j.1745-9133.2010.00621.x

Futter, Lydia. 2008. "Child Trafficking in South Africa." Pp. 198-210 in Child and Youth Misbehavior in South Africa: A Holistic Approach, $2^{\text {nd }}$ Edition, edited by $C$. Bezuidenhout and S. Joubert. Pretoria: Van Schaik. 
Government Gazette: Republic of South Africa. (2013) Vol. 577, No. 36715. Cape Town: Government printers.

International Labour Organization (ILO).2012. ILO 2012 Global Estimate of Forced Labour.

International Organization for Migration (IOM). 2003.Seduction, Sale and Slavery: Trafficking in Women and Children for Sexual Exploitation in Southern Africa, $3^{\text {rd }}$ ed. Pretoria: IOM.

Lanier, Mark M. 2006.The Impact of HIVIAIDS on Criminology and Criminal Justice. Hampshire, UK: Ashgate Publishing.

Lanier, Mark M., Karol Lucken and Timothy Akers. 2010. "Further Need for Epidemiological Criminology." Pp. 163-174 in Key Correctional Issues, $2^{\text {nd }}$ Edition, edited by R. Muraskin. Surrey, UK: Prentice Hall Publishing.

Lanier, Mark M., Robert P. Pack, Timothy A. Akers. 2010. "Epidemiological Criminology: Drug Use Among African American Gang Members." Journal of Correctional Health Care 16(1): 6-16. http://dx.doi.org/10.1177/1078345809348199

Lanier, Mark M., C. Thomas Farrell. 2014. "A Mixed Methods Analysis of Human Trafficking." Journal of Social Science Research, forthcoming.

Mehta, Resh. 2013. "Child Trafficking in South Africa." Pp. 238-254 in Child and Youth Misbehaviour in South Africa: A Holistic View, $3^{\text {rd }}$ Edition edited by C. Bezuidenhout. Pretoria: Van Schaik.

Nazemi, Nazafarin. 2012. "How globalization facilitates trafficking in persons?." Acta Universitatis Danubius. Communicatio 6(2): 5-14.

Rittossa, Dalida. 2009. "Trafficking of Minors in Croatia: Present Situation." European Journal of Crime, Criminal Law \& Criminal Justice 17(2):137-164. http://dx.doi.org/10.1163/157181709X429123
Simon, Sonide. 2008. "Human Trafficking and Florida Law Enforcement." Florida Criminal Justice Executive Institute. Florida Department of Law Enforcement. Tallahassee, FL.

Swart, Dawie. 2012. "Human Trafficking and the Exploitation of Women and Children in a Southern and South African Context." Child Abuse Research in South Africa 13(1):62-73.

Todres, Jonathan. 2011. "Widening Our Lens: Incorporating Essential Perspectives in the Fight Against Human Trafficking." Michigan Journal of International Law 33(1):53.

United States Department of State. 2010. Trafficking in Persons Report, Tenth Edition. Washington, DC.

United States Department of State. 2013. The State Department 2013 Trafficking in Persons Report. Washington, DC.

\section{Informative Reports are also Available Through these Links}

http://www.theiacp.org/portals/0/pdfs/CompleteHTGuide.pdf

http://www.policechiefmagazine.org/magazine/index.cfm?fuseaction= display_arch\&article_id $=174 \&$ issue_id $=122003$

https://www.fdle.state.fl.us/Content/getdoc/e77c75b7-e66b-40cdad6e-c7f21953b67a/Human-Trafficking.aspx

http://dcf.state.fl.us/programs/humantrafficking/docs/coalitions.pdf https://www.unodc.org/unodc/en/human-trafficking/publications.html http://uir.unisa.ac.za/bitstream/handle/10500/10189/thesis_mollema_ n.pdf?sequence $=1$

\section{DOI: http://dx.doi.org/10.6000/1929-4409.2014.03.23}

(c) 2014 Lanier et al.; Licensee Lifescience Global.

This is an open access article licensed under the terms of the Creative Commons Attribution Non-Commercial License (http://creativecommons.org/licenses/by-nc/3.0/) which permits unrestricted, non-commercial use, distribution and reproduction in any medium, provided the work is properly cited. 